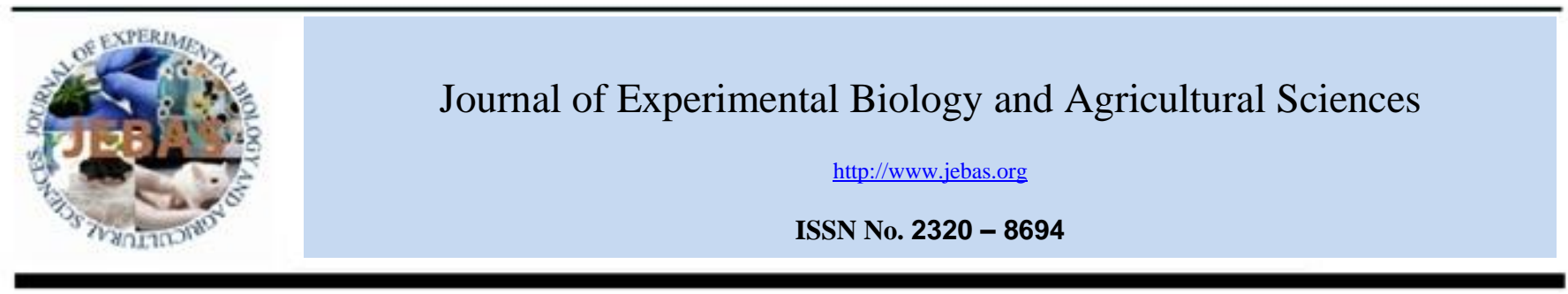

\title{
WATER QUALITY IN AQUACULTURE AND NON-AQUACULTURE SITES IN TAAL LAKE, BATANGAS, PHILIPPINES
}

\section{Blesshe L Querijero $^{1, *}$ and Airill L Mercurio ${ }^{2}$}

\begin{abstract}
${ }^{1}$ Animal Biology Division, Institute of Biological Sciences, College of Arts and Sciences, University of the Philippines, Los Baños 4031, Laguna, Philippines ${ }^{2}$ Biological Sciences Department, College of Science and Computer Studies, De La Salle University-Dasmariñas, City of Dasmariñas 4114, Cavite, Philippines
\end{abstract}

Received - January 06, 2016; Revision - January 27, 2016; Accepted - February 20, 2016

Available Online - February 20, 2016

DOI: http://dx.doi.org/10.18006/2016.4(1).109.115

\begin{tabular}{|c|c|}
\hline & \\
\hline KEYWORDS & ABSTRACT \\
\hline Fish cages & Aquaculture activities are often blamed for the degradation of water quality of aquatic ecosystem. \\
\hline Taal Lake & $\begin{array}{l}\text { Present study was conducted to determine the water quality of Taal Lake at two different study sites viz. } \\
\text { one under intense fish cage farming activities and the other without aquaculture activities. The study }\end{array}$ \\
\hline $\begin{array}{l}\text { Physico-chemical } \\
\text { characteristics }\end{array}$ & $\begin{array}{l}\text { aims to assess the effect of aquaculture activities on selected water quality parameters, which include } \\
\text { transparency, temperature, } \mathrm{pH} \text {, nitrates, phosphates, salinity, total dissolved solids (TDS) and dissolve } \\
\text { oxygen (DO). The study was conducted over a ten-month period in 2013-2014. Results of the study }\end{array}$ \\
\hline Water quality & $\begin{array}{l}\text { revealed no significant differences in water temperature, } \mathrm{pH} \text {, salinity, transparency and DO between the } \\
\text { aquaculture and non-aquaculture sites of the lake, although } \mathrm{DO} \text { and transparency were consistently }\end{array}$ \\
\hline Aquaculture & $\begin{array}{l}\text { lower in the aquaculture sampling stations throughout the } 10 \text {-month sampling period. DO dipped to } \\
\text { critical level ( }<4 \mathrm{ppm}) \text { for aquatic organisms in the months of January and February. Nitrates, } \\
\text { phosphates and TDS were significantly higher in the area with fish cage farming activities as compared } \\
\text { to the non aquaculture site. Further, the study also reports the efforts of stakeholders to sustain fish cage } \\
\text { farming in the lake which include participative, multi-sectoral action planning, information and } \\
\text { education, policy formulation, regulation and licensing. }\end{array}$ \\
\hline
\end{tabular}

* Corresponding author

E-mail: blessheq42@yahoo.com (Blesshe L Querijero)

Peer review under responsibility of Journal of Experimental Biology and Agricultural Sciences.

Production and Hosting by Horizon Publisher (http://publisher.jebas.org/index.html).

All rights reserved.
All the article published by Journal of Experimental Biology and Agricultural Sciences is licensed under a Creative Commons Attribution-NonCommercial 4.0 International License Based on a work at www.jebas.org.

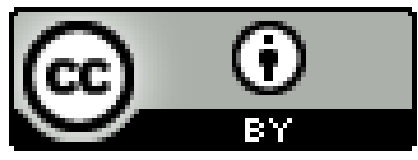




\section{Introduction}

Among various resource based activities in and around the lake, including its watershed areas, aquaculture activities are often blamed for the degradation of water quality (Pullin, 1993). Aquaculture also supports food security and livelihood. Reducing vulnerability of aquaculture production due to water quality deterioration by fishing is a national priority for a sustainable fish production (Jacinto, 2011). Taal Lake has an area of $268 \mathrm{~km}^{2}$ with an aquatic surface area of $236.9 \mathrm{~km}^{2}$ and a maximum depth of $198 \mathrm{~m}$ (Castillo \& Gonzales, 1976). It is the third largest freshwater lake in the Philippines. It provides multiple services to various users, among these fisheries is one of the most dominant one with floating fish cages for tilapia Oreochromis niloticus and milkfish Chanos chanos. Intensive aquaculture and human activities caused deterioration of the water quality of the lake and fish kills have become more common incidents in Taal Lake (Jacinto 2011, Macandog et al., 2014). In 2011 these incidences of fish kills in Taal Lake were reported during May to June and killed more than 2,000 tons of farmed fish. Over 7,000 illegally operated fish cages were dismantled by a multi-agency task force (BFAR 2014).

The changes in the physico-chemical properties of the water of Taal Lake were reported in several studies (Zafaralla et al., 1992, Alcañices et al., 2001, Vista et al., 2006, Rosana et al., 2008, Papa \& Mamaril, 2011). According to Galera \& Martinez (2011), the water surface temperature, $\mathrm{pH}$, total dissolved solids, total suspended solids, color and dissolved oxygen of Taal lake in 2009 conformed the class C water standards (DENR AO 34, 1990); and was therefore safe for aquaculture use, and for primary contact recreation such as bathing, swimming and skin diving.
This study was undertaken to determine and compare the physico-chemical characteristics of Taal Lake in aquaculture and non-aquaculture sites and tried to find out the effects of fish cage farming on water quality as valuable inputs for policy decisions pertaining to aquaculture production in the lake. The study also aimed to document the stakeholders' efforts to sustain aquaculture production in the lake and prevent degradation of water quality.

\section{Materials and Methods}

\subsection{Assessment of Water Quality}

Selected physico-chemical characteristics of Taal lake water at the aquaculture and non-aquaculture sites of the lake were determined monthly for 10 months from August 2013 to May 2014 using standard procedures. The physical parameters include water transparency and temperature while the chemical parameters include $\mathrm{pH}$, nitrates, phosphates, salinity, total dissolved solids (TDS) and dissolved oxygen (DO) were studied throughout the study period. Figure 1 shows the sampling sites, the sampling stations for the aquaculture sites were located in three Barangays i.e. Sampaloc, Aya and Berinayan. Among these, Sampaloc and Aya are in the municipality of Talisay while Berinayan in Laurel municipality. Both municipalities are located in Batangas province, Philippines. The non-aquaculture sampling stations were located in Barangay Wawa, Tanauan municipality, Batangas (Figure 1). Each Barangay had three sampling stations to serve as triplicate sampling stations or a total of 12 sampling stations. Sampling was done once every month. A GPS Garmin E-trex ${ }^{\circledR}$ Global Positioning Device was used to identify and mark the sampling stations.

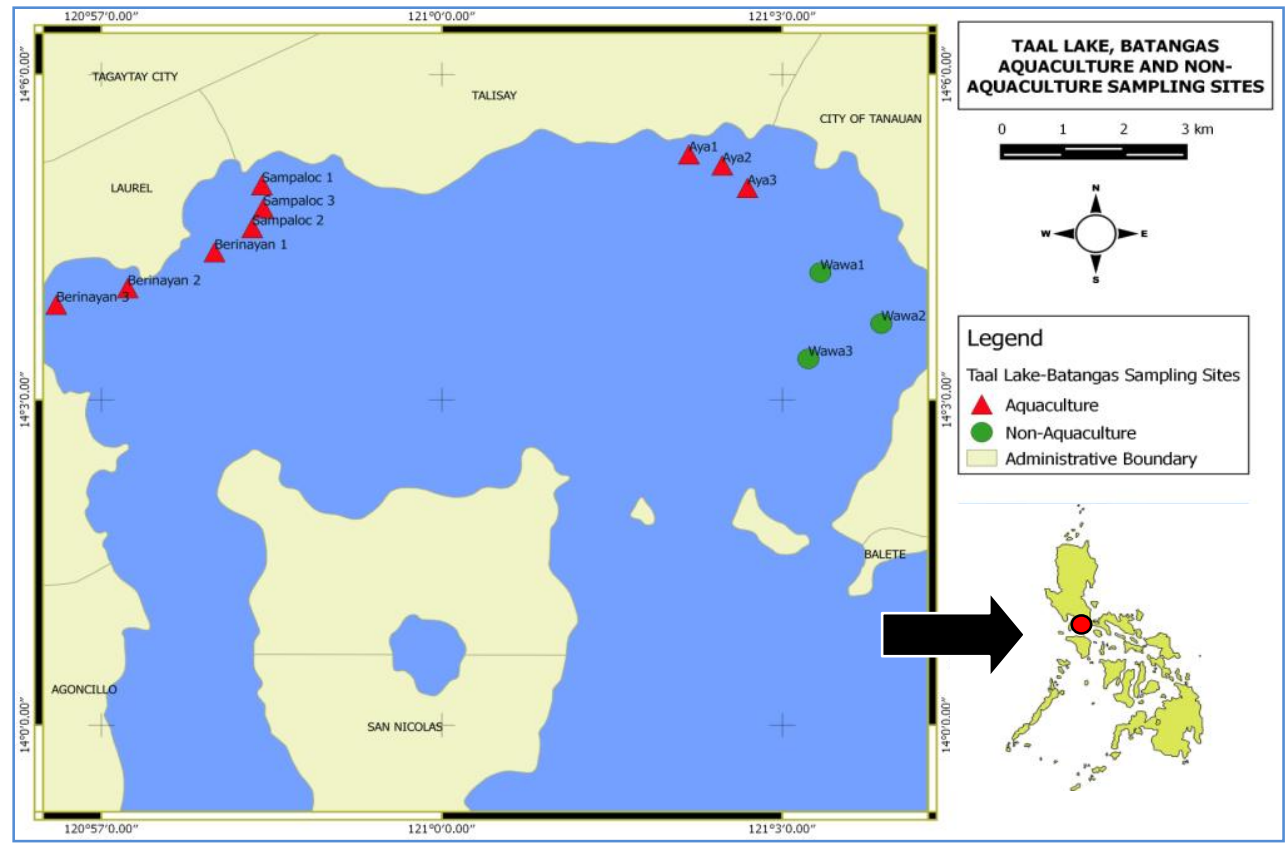

Figure 1 Overview of Taal Lake, Philippines and the water sampling stations 
Measurement of physico-chemical parameters of water was carried out in situ, at the surface and at $10 \mathrm{~m}$ depth. Water samples for chemical analysis were collected from the surface. In aquaculture sites, measurements of parameters were done inside fish cages. All of the physico-chemical parameters were taken in triplicates from each of the sampling stations. Sampling was carried out between 9 A.M to 2 P.M.

Among physical characteristics, the water temperature was determined using standard laboratory thermometer at the sampling site only while the water transparency was measured by a $3.3 \mathrm{~kg}$ metal plate Secchi disk. For chemical characteristics, dissolved oxygen was measured by using DO meter (YSI 550A ${ }^{\circledR}$ ) with 10 meters length cable, similarly pH, salinity, conductivity and total dissolved solids (TDS) were also measured by same length holding SCT pH meter (YSI EC300A ${ }^{\circledR}$ ). The nitrates and phosphates were measured using $\mathrm{HACH}$ DR/890 portable colorimeter. The nitrate and phosphate contents of the lake water were measured using nitrates and phosphates reagents tested in a $10 \mathrm{ml}$ vials collected from each sampling stations (Umaly, 1988). Quantitative data on water quality parameters were compared using Mann-Whitney U test at $95 \%$ level of confidence to determine significant difference between aquaculture and nonaquaculture sites.

2.2 Fish Farmers' Practices and Stakeholders' Efforts Affecting Water Quality

A total of 20 key respondents were interviewed for their current fish farming practices for exploring the effect of farming practices on the water quality such as fish stocking densities and feeding management. Interviewed key informants were fish cage owners, caretakers, members of the Taal Lake Aquaculture Alliance Incorporated (TLAAI), municipal agricultural and fisheries officers of the selected municipalities and from relevant Philippine government agencies such as the Bureau of Fisheries and Aquatic Resources (BFAR-IVA) and the Taal Volcano Protected Landscape (TVPL) of the Department of Environment and Natural Resources, Philippines (DENR).

\section{Results and Discussion}

\subsection{Assessment of Water Quality}

Results of the study revealed no significant differences in water transparency, temperature, $\mathrm{DO}, \mathrm{pH}$, and salinity between aquaculture and non-aquaculture sites throughout the 10-month sampling period, except in nitrates, phosphates levels and in total dissolved solids where significant differences existed (Table 1 and Figure 2). DO and transparency were consistently lower in the aquaculture sampling stations although not significantly different from the non-aquaculture sampling stations.

\subsubsection{Phosphates}

The levels of phosphate was reported higher than the standard DENR $(0.05-1.0 \mathrm{mg} / \mathrm{L})$ recommended for Class C waters (aquaculture purpose) for both study sites during the entire sampling period. Average monthly phosphate levels during the 10-month sampling period were significantly higher $(2.17 \mathrm{mg} / \mathrm{L})$ in the aquaculture areas than in the nonaquaculture areas $(1.91 \mathrm{mg} / \mathrm{L})$ (Figure 2). Higher phosphates level was observed during the months of September to October 2013, it may be because of heavy rains during these months. Zafaralla (1993) and Alcañices et al. (2001) observed an increase in nutrient concentration during the entire wet season and in this manner results of present study are in agreement with the findings of these researchers.

Table 1 Average values of the physico-chemical parameters of the water in aquaculture and non-aquaculture sampling stations in Taal Lake from August 2013- May 2014.

\begin{tabular}{|c|c|c|c|c|}
\hline \multirow[t]{2}{*}{ Parameter } & \multirow[t]{2}{*}{ Units } & \multirow{2}{*}{$\begin{array}{l}\text { Standard Level for Class } \\
\text { C Water* }\end{array}$} & \multicolumn{2}{|c|}{ Mean $( \pm \mathbf{S D}) * * * *$} \\
\hline & & & Aquaculture & Non-aquaculture \\
\hline Phosphates & $\mathrm{mg} / \mathrm{L}$ & $0.05(0.1)^{* *}$ & $2.17^{\mathrm{a}} \pm 0.45$ & $1.91^{\mathrm{b}} \pm 0.23$ \\
\hline Nitrates & $\mathrm{mg} / \mathrm{L}$ & 10 & $2.93^{\mathrm{a}} \pm 0.53$ & $2.197^{\mathrm{b}} \pm 0.61$ \\
\hline Total Dissolved Solids (TDS) & $\mathrm{mg} / \mathrm{L}$ & 1000 & $1127.37^{\mathrm{a}} \pm 60.70$ & $1066.41^{\mathrm{b}} \pm 56.90$ \\
\hline Dissolved Oxygen (DO) (minimum) & $\mathrm{mg} / \mathrm{L}$ & 5.0 & $5.67^{\mathrm{a}} \pm 1.40$ & $6.73^{\mathrm{a}} \pm 1.72$ \\
\hline $\mathrm{pH}$ & - & $6.5-8.5$ & $8.45^{\mathrm{a}} \pm 0.47$ & $8.25^{\mathrm{a}} \pm 0.66$ \\
\hline Salinity & $\mathrm{ppt}$ & & $0.82^{\mathrm{a}} \pm 0.42$ & $0.82^{\mathrm{a}}+0.23$ \\
\hline Transparency & Meter & & $2.52^{\mathrm{a}} \pm 1.38$ & $3.13^{\mathrm{a}} \pm 1.71$ \\
\hline Water Temperature & ${ }^{\circ} \mathrm{C}$ & $3{ }^{\circ} \mathrm{C}$ rise & $28.35^{\mathrm{a}}+1.98$ & $28.14^{\mathrm{a}} \pm 1.96$ \\
\hline
\end{tabular}

${ }^{*}$ Class $\mathrm{C}$ water is described as water for fishery propagation and growth of fish and other fishery products; for recreation and industrial supply for manufacturing processes (DENR AO 34, 1990), **Values in parenthesis are considered maximum values for lakes and reservoirs (DENR AO 34, 1990), *** Average values with the different letters as superscript on the same row indicated significant difference $(\mathrm{p}>0.05)$ among the treatments 
According to Hilario \& Perez (2013) intensive fishing is a point source of dissolved inorganic nutrients principally nitrogen and phosphorus, and that wind stress was responsible for the slow nutrient transport in Taal lake. Further, Lucas \& Southgate (2012) reported that phosphorus occurred in water primarily as phosphate ion and in combination with organic matter which phytoplankton assimilated and caused their bloom. Other point sources of phosphates and nitrates in lakes were domestic wastes that include washing detergents and faecal matter, and agricultural run-off with fertilizers and liquid manure from livestock.

\subsubsection{Nitrates}

Nitrates levels inside fish cages ranged from $1.76 \mathrm{mg} / \mathrm{L}$ to 3.69 $\mathrm{mg} / \mathrm{L}$ and were significantly higher than in non-aquaculture site. These values are higher than previous studies in Taal lake (Zafaralla et al., 1992; White et al., 2007; Rosana et al., 2008). In an earlier study, Dela Vega (2001) reported that for every $1,000 \mathrm{~kg}$ of feed used, an estimated $47 \mathrm{~kg} \mathrm{~N}$ and $9 \mathrm{~kg} P$ were lost into the water. The unconsumed food from fish cage aquaculture settled at the bottom of the lake.

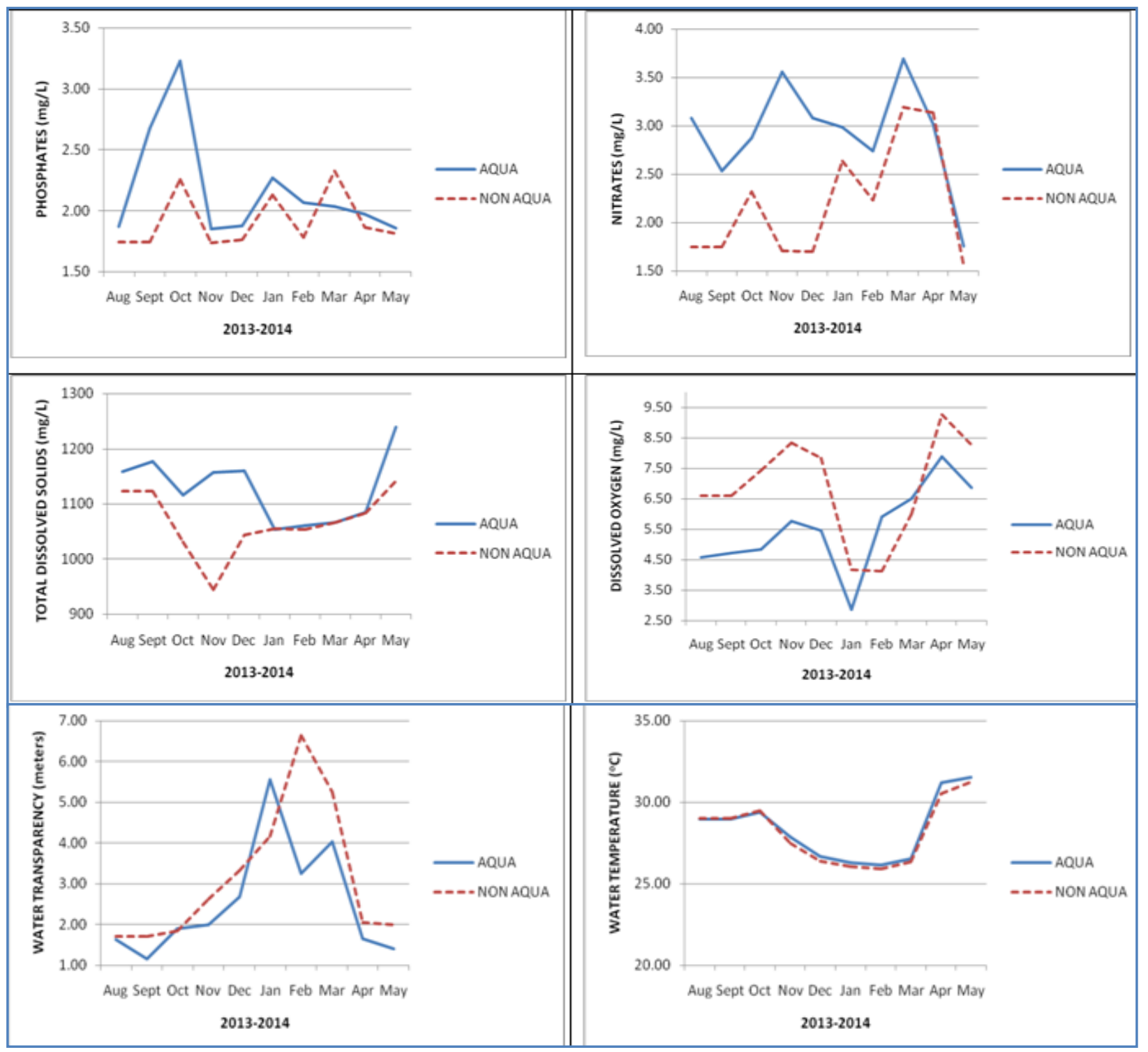

Figure 2 Physico-chemical parameters (phosphates, nitrates, total dissolved solids, dissolved oxygen, water transparency, and water temperature) in fish cage farming areas (aquaculture) and in the non- aquaculture area in Taal Lake, Philippines from August 2013 to May 2014. 
3.1.3 Total dissolved solids (TDS)

Freshwater usually have a TDS concentration less than $1000 \mathrm{mg} / \mathrm{L}$. The TDS concentrations at both sites were above $1000 \mathrm{mg} / \mathrm{L}$ and it was significantly highest during May with the start of the rainy season. These dissolved solids are inorganic substances which are available in ionic form. According to Lucas \& Southgate (2012) rainfall and soil particles that are washed into the water from run-off are also sources of TDS.

\subsubsection{Water Transparency}

Although water transparency was not significant different between these two sites, the monthly water transparency at non-aquaculture sites were consistently higher than those from the aquaculture sites. It was reported highest in the months of January and February, 2014, which coincided with phytoplankton die off starting January to March 2014. Present study showed lower transparency value $(1.15 \mathrm{~m}$ to $5.56 \mathrm{~m})$ as compared to the previous studies of Zafaralla et al., 1992 (7.8 m), Alcañices et al., 2001 (5m), Vista et al., 2006 (4-6m). Findings of present study are in agreement with the findings of Rosana et al. (2008), those have reported $3.44 \mathrm{~m}$ transparency in open water areas while this value was $2.92 \mathrm{~m}$ in cage farming areas. Water transparency value less than $2.0 \mathrm{~m}$ is considered a eutrophic lake (US EPA 1974). Taal lake transparency values were lower than $2.0 \mathrm{~m}$ for several months during the 10-month sampling period so it can be considered as eutrophic lake (Figure 2).

\subsubsection{Dissolved Oxygen}

Lowest DO level was recorded in the month of January 2014, on the same month when water transparency value was found to be the highest. This can be attributed to the start of phytoplankton die-off in the lake. DO levels below $4 \mathrm{ppm}$ were observed in January -February, 2014 in aquaculture site. DO measurements were taken during the mid-morning hours yet DO levels were below $5 \mathrm{mg} / \mathrm{L}$. This implies that there exists only a small margin of safety before the fish are exposed to a critical DO level of below $4 \mathrm{mg} / \mathrm{L}$. DO level may become even critically low in late evening or during early morning hours in the absence of photosynthesis, and in the presence of high standing fish biomass inside cages and it may result to fish kill.

Phytoplankton die-off occurred in January-February, 2014, followed by fish kill on the same months. Increasing the level of DO above $6 \mathrm{mg} / \mathrm{L}$ in aquaculture sites and $8 \mathrm{mg} / \mathrm{L}$ in nonaquaculture sites in March-May 2014 may be due to decrease in the overall fish standing stock in the lake as a result of fish kill and the light to moderate phytoplankton density during these months (Mercurio et al., 2016).

\subsubsection{Water Temperature}

Water surface temperature ranged from $26^{\circ} \mathrm{C}$ to $31^{\circ} \mathrm{C}$, without significant differences between the two study sites. Similar type of result was reported by Papa \& Mamaril (2011) for Taal lake. Lowest water temperature was reported during February 2014 while the highest was during the month of May 2014.

\section{$3.1 .7 \mathrm{pH}$}

The pH ranged from 7.5 to 9.14 and did not statistically differ between the two study sites. The lake is known to be of volcanic origin with annual water overturn and occasional acid sulphate emission which could result to low water $\mathrm{pH}$ condition. The $9.1 \mathrm{pH}$ value observed in the present study were similar to the findings of Rosana et al. (2008).

\subsubsection{Salinity}

Salinity in Taal lake was 0.8-0.9 ppt, uniform throughout the entire sampling period in both study sites and it considered as freshwater.

\subsection{Fish Farmers' Practices and Stakeholders Efforts Affecting} Water Quality

Results of the study on farming practices showed efforts of fish farmers and stakeholders to reduce organic loading in the lake. Fish farmers were required to attend a government sponsored seminar on Good Aquaculture Practices (GAP) before permit to operate a fish cage was given to prospective fish cage farmers. Regular consultation and information campaign on good aquaculture practices particularly on reducing feed losses were also conducted by various stakeholders. A consultative Unified Rules and Regulation on Fisheries (URRF) in Taal Lake was drafted and approved on July 2014 as part of the Taal Volcano Protected Landscape (TVPL) management plan. URRF sets a limit to 6,000 floating cages in Taal lake, distributed to the various municipalities and this distribution was as follows: Talisay $-2,000$ cage units; Laurel $-1,350$; Agoncillo - 1,500; San Nicolas - 1,000; Mataas na Kahoy 120; Cuenca - 20. A cage unit measures $10 \mathrm{~m} \times 10 \mathrm{~m} \times 10 \mathrm{~m}$. For the circular type, a diameter of $16 \mathrm{~m}$ and depth of $10 \mathrm{~m}$ is allowed. URRF also mandated the use of extruded floating feed starting March 2015 to reduce feed loss.

The recommended maximum stocking density for tilapia in cages in Taal Lake is $50 \mathrm{pcs} / \mathrm{m}^{3}$ or $50,000 /$ cage and for milkfish is $14 \mathrm{pcs} / \mathrm{m}^{3}$ or $14,000 /$ cage. Unfortunately, some fish farmers opted to have higher fish stocking density than recommended. Overfeeding increases production cost and nutrient loading to the environment (Dela Vega \& Querijero, 2005; Bunting, 2013). White (2013) emphasized the importance of significantly reducing the production Feed Conversion Ratio (FCR) values to minimize feed costs and feed loss. Feed costs account for more than 60 percent of total production costs. Feed loss and fish wastes from intensive fish cage farming may have negatively affected the quality of water particularly the levels of nitrates, phosphates, transparency and 
dissolved oxygen in the aquaculture sites as shown in the present study.

\section{Conclusions}

Aquaculture activities like fish cage farming affect water quality as indicated by the significantly higher levels of nitrates, phosphates and TDS and the consistently low DO and transparency values in aquaculture sites compared to nonaquaculture sites. To sustain aquaculture production in Taal lake, stakeholders need to continue their collaborative, multisectoral action planning, information and education campaign, regulation and licensing that are backed up with sound data on water quality and feedback.

\section{Acknowledgements:}

The authors acknowledge the University Research Office (URO) of De La Salle University-Dasmariñas (DLSUD) for providing financial support; and the Bureau of Fisheries Region IVA, particularly Ms. Nenita S. Kawit of the Inland Fisheries Research Station; the local government units of Talisay and Laurel; the PASu TVPL Office and Mr. Victor H. Mercado, and the TLAAI for kind assistance.

\section{Conflict of Interest}

Authors would hereby like to declare that there is no conflict of interests that could possibly arise.

\section{References}

Alcañices MM, Pagulayan RC, Mamaril AC (2001) Impact assessment of cage culture in Lake Taal, Philippines. In: Santiago CB, Cuvin-Aralar ML, Basiao ZU (Eds.) Conservation and Ecological Management of Philippines Lakes in Relation to Fisheries and Aquaculture. SEAFDECPCAMRD-BFAR, Philippines, Pp.153.

Bunting SW (2013) Principles of sustainable aquaculture: Promoting social, economic and environmental resilience. Routledge. New York.

Bureau of Fisheries and Aquatic Resources (BFAR) (2014) Available on www.bfar.da.gov.ph access on $28^{\text {th }}$ December 2015.

Castillo B, Gonzales C (1976) Hydrology of Taal Lake. Fisheries Research Journal of the Philippines 1: 62-75.

De la Vega JT (2001) Feeds and feeding management of tilapia in cages. Paper presented at the $4^{\text {th }}$ Southern Luzon Zonal R and D Review, DAP Tagaytay City Philippines.

Dela Vega A, Querijero BL (2005) Industry Perspective: Practices and Needs in Feeds and Feeding Management including Financing Schemes in Cage and Pen Operations
(Bolinao, Pangasinan Experience). In: Querijero BL, Pagdilao $\mathrm{CR}$, Ilagan S (Eds.) Guidelines for Establishment of Fish Cages and Other Structures in Lakes and Coastal Waters. PCAMRD Book Series No. 36/ 2005, Pp.90-101.

Department of Environment and Natural Resources (DENR), Philippines, Administrative Order No. 34. Series of 1990 (1990) Revised Water Usage and Classification/ Water Quality Criteria.

Galera IC, Martinez FV (2011) Monitoring and evaluation of the water quality of Taal Lake, Talisay, Batangas, Philippines. Journal of Academic Research 1 : 229-236.

Hilario JE, Perez TR (2013) Predicting transport of nutrients from three tributary rivers of Taal lake Philippines. The Philippine Agricultural Scientist 96 : 60-70.

Jacinto GS (2011) Fish kill in the Philippines. Science Diliman $23: 1-3$.

Lucas JS, Southgate PC (2012) Aquaculture: Farming Aquatic Animals and Plants. Blackwell Publishing. John Wiley and Sons, UK. Pp. 648.

Macandog DM, Dela Cruz CPP, Edrial JD, Reblora MA, Pabico JP, Salvacion AR, Marquez TL, Macandog PBM, Perez DKB (2014) Eliciting local knowledge and community perception on fishkill in Taal Lake through participatory approaches. Journal of Environmental Science and Management 17: 1-16.

Mercurio AL, Querijero BL, Ching JA (2016) Phytoplankton community in aquaculture and non-aquaculture sites of Taal lake, Batangas, Philippines. Journal of Experimental Biology and Agricultural Sciences 4: 66-73. doi: http://dx.doi.org/10.18006/2015.4(1).66.73.

Papa RS, Mamaril AC (2011) History of the biodiversity and limno-ecological studies on Lake Taal with notes on the current state of Philippine limnology. Philippine Science Letters 4(1):1-10.

Pullin RSV (1993) An overview of environmental issues in developing-country aquaculture. In: Pullin RSV, Rosenthal H, Maclean JL (Eds.) Environment and Aquaculture in Developing Countries. ICLARM Conference Proceeding 31/1993. Pp.1-19.

Rosana MR, Clemente JP, Casao EA, Regpala RR, Kawit NS, Panisales VD (2008) Primary productivity, phytoplankton and the development of eutrophic state of Taal Lake, Southern Luzon, Philippines. In: Inland Fisheries Research Station Project Report, Bureau of Fisheries and Aquatic Resources Region IV-A, Ambulong, Tanauan City, Batangas, Philippines. 
Umaly RC (1988) Limnology: Laboratory and Field Guide Physico-chemical factors and Biological factors. National Bookstore, Philippines.

United States Environmental Protection Agency (US EPA) (1976) Quality criteria for water. Washington, D.C. USA.

Vista A, Norris P, Lupi F, Bernstern R (2006) Nutrient loading and efficiency of tilapia cage culture in Taal Lake, Philippines. The Philippine Agricultural Scientist 89: 48-57.

White P (2013) Environmental consequences of poor feed quality and feed management. In: Hasan MR, New MB (Eds.) On-farm feeding and feed management in aquaculture. FAO Fisheries and Aquaculture Technical Paper No 583, Rome, FAO Pp. 553-564.
White P, Christensen GN, Palerud R, Legovic T, Rosario WR, Lopez N, Regpala RR, Gecek S, Hernandez J (2007) Environmental monitoring and modelling of aquaculture in risk areas of the Philippines. Available on http://aquaculture.asia/files/D8_EMMA_Taal_final_report.pdf on 6th December, 2016.

Zafaralla M, Santos R, Torreta N, Regalado M, Orozco R (1992) Influence of water quality and phytoplankton community structure in Taal Lake. Fisheries Research Journal of the Philippines 17: 75-91.

Zafaralla, M (1993) Limnological assessment of Taal Lake. Research Project Report. UPLB, College, Laguna, Philippines, Pp. 218. 